The Psychological Record, 2009, 59, 489-510

\title{
THE EMPATHY IMBALANCE HYPOTHESIS OF AUTISM: A THEORETICAL APPROACH TO COGNITIVE AND EMOTIONAL EMPATHY IN AUTISTIC DEVELOPMENT
}

\author{
Adam Smith \\ Dundee, Scotland
}

\begin{abstract}
There has been a widely held belief that people with autism spectrum disorders lack empathy. This article examines the empathy imbalance hypothesis (EIH) of autism. According to this account, people with autism have a deficit of cognitive empathy but a surfeit of emotional empathy. The behavioral characteristics of autism might be generated by this imbalance and a susceptibility to empathic overarousal. The EIH builds on the theory of mind account and provides an alternative to the extreme-male-brain theory of autism. Empathy surfeit is a recurrent theme in autistic narratives, and empirical evidence for the EIH is growing. A modification of the pictorial emotional Stroop paradigm could facilitate an experimental test of the EIH.
\end{abstract}

Autism is a pervasive developmental disorder that continues to fascinate researchers, challenge clinicians, and distress affected families. Empathy is a set of processes and outcomes at the heart of human social behavior. Fascination with autism is often interwoven with the study of empathy because prevailing theory suggests that people with autism lack empathy. For example, according to Decety and Jackson (2004), "Children with autism ... display a broad range of social communication deficits, and most scholars agree that a lack of empathy prominently figures amongst them" (p. 90). The empathy imbalance hypothesis (EIH) of autism, in keeping with the theory of mind hypothesis (Baron-Cohen, 1995), proposes that autism involves a significant cognitive empathy (CE) deficit. However, the hypothesis also proposes, in contrast to prevailing theory, that people with autism actually have a heightened capacity for basic emotional empathy (EE). This combination of a CE deficit and an EE surfeit can be termed EE-dominated empathic imbalance.

The purpose of this article is to refine and expand the EIH of autism. To do this, I first tackle some definitional issues and describe the origin of the hypothesis. I then argue that the EIH may help account for many psychological features of autism. Evidence for the EIH will include the following: (a) Children with autism show more facial affect than typically developing children in an empathy paradigm study, (b) the faces of adults with autism show heightened electromyographic responsiveness to other

Correspondence concerning this article should be addressed to Adam Smith, 7 Faraday St., Dryburgh Industrial Estate, Dundee DD2 3QQ, Scotland, UK. E-mail: adamjamessmith@fsmail.net. 
people's expressions of happiness and fear, (c) children with autism show appropriate electrodermal responses to images of distressed people and sometimes refuse to look at such images, (d) adults with Asperger syndrome report high levels of personal distress in response to others' suffering, (e) results from eye-tracking and physiological studies are consistent with the claim by people with autism that it is painful for them to make eye contact with others, and (f) practitioners and caregivers perceive some people with autism as being highly sensitive to the emotions of others. Finally, I suggest that a novel emotional Stroop paradigm could be used to test the hypothesis.

\section{Defining Empathy and Autism}

\section{Empathy}

CE is the ability to understand and predict the behavior of others in terms of attributed mental states, particularly epistemic mental states such as believing, knowing, pretending, and guessing. Similarly, Blair (2005) wrote that the term $C E$ is used when "the individual represents the internal mental state of another individual" (p. 699). CE is thus synonymous with theory of mind or mentalizing (Baron-Cohen, 2003; Blair, 2005).

EE is an emotional response in an individual that stems from and parallels the emotional state of another individual. Similarly, Hoffman (2000) defined empathy as "an affective response more appropriate to another's situation than one's own” (p. 4). More recently, De Vignemont and Singer (2006) defined EE using four criteria:

There is empathy if (i) one is in an affective state; (ii) this state is isomorphic to another person's affective state; (iii) this state is elicited by the observation or imagination of another person's affective state; (iv) one knows that the other person is the source of one's own affective state. (p. 435)

Emotional responses that meet only the first three criteria are sometimes called emotional contagion, not empathy (e.g., see Bischof-Kohler, 1991; Eisenberg, 2000). However, the knowledge referred to in the fourth criterion is unlikely to be an absolute phenomenon, and, as Eisenberg and Strayer (1987) pointed out, "even young children may have some primitive understanding of the difference between their own and others' affective responding" (p. 6). Pure emotional contagion can meet Hoffman's definition of empathy, and a rigid distinction between empathy and emotional contagion is probably not viable (see Preston \& De Waal, 2002).

Some definitions of empathy combine CE and EE. According to BaronCohen (2002), empathizing is "the drive to identify another person's emotions and thoughts, and to respond to these with an appropriate emotion" (p. 248). Notice that this definition presents CE as the first step in empathizing and EE as a second step.

In this article, I distinguish between direct EE (i.e., spontaneous EE not derived from $\mathrm{CE}$ ) and indirect EE (i.e., EE derived from CE). Direct EE can occur as a response to overt cues, such as another's facial expressions or emotional vocalizations. Indirect EE depends on an understanding of another's mental state and involves the ability to share an emotional state 
that is inferred but not observed. With direct EE, the empathizer may or may not be fully aware that he or she is sharing the emotion of another. (In other words, direct EE may or may not be complemented by some degree of CE.) Direct EE is particularly relevant to the sharing of basic emotions, such as happiness, sadness, fear, and anger. Indirect EE may involve basic emotions or more complex emotions, such as guilt and shame (although not all emotion theorists accept the distinction between basic and complex emotions; see Sloboda \& Juslin, 2001).

Davis (1996) distinguished between the parallel and the reactive affective outcomes of empathy. These reactive outcomes can be derived from EE (see Davis, 1996; Eisenberg, 2000) and include empathic concern and personal distress. Empathic concern (sometimes called sympathy) is a compassionate desire to relieve the suffering of another (e.g., Eisenberg, 2000). Personal distress is a self-oriented experience of discomfort that stems from another's emotional state and often involves the observer feeling hopeless or incompetent in response to a target's suffering. Returning to Baron-Cohen's definition of empathizing, we can see that an appropriate emotional response could be either parallel or reactive, although it is clear that personal distress is much less appropriate than EE or empathic concern. More detailed guidance through the definitional minefield is available elsewhere (e.g., Davis, 1996; Eisenberg, 2000; Eisenberg \& Strayer, 1987).

\section{Autism}

Autism is a lifelong disorder diagnosed in children who display a particular pattern of behavioral characteristics (e.g., Cooper, 1994). Warning signs of autism in preschool children include delayed language development, a lack of awareness of others, a lack of pretend play, and a failure to respond to the feelings and facial expressions of others (Scottish Intercollegiate Guidelines Network, 2007). Children with autism fail to develop typical peer relationships and are impaired in their capacity to use nonverbal behaviors to regulate social interaction. People with autism often develop narrow or unusual interests and resist changes to their daily routines. Stereotypic patterns are an important feature of autistic behavior.

Relatively severe cases of autism spectrum disorder are sometimes called classic autism. People with autism are described as high-functioning if they have an IQ in the normal range. Asperger syndrome appears to be a form of high-functioning autism that does not involve delayed language development (see Happe, 1994).

\section{Origin of the Hypothesis}

The EIH of autism originates from a theoretical approach to the mental relationship between CE and EE (Smith, 2006). I argued that natural selection probably acted on variation in the relationship between CE and EE during human evolution. Imagine a population in which each individual has a capacity for both CE and EE and in which the relationship between the two capacities varies from individual to individual. Natural selection will act on the relationship between CE and EE if the variation has a slight genetic basis and makes a slight contribution to differential survival and reproduction. Tiny selective advantages can result in evolutionary change (Pinker \& Bloom, 1992). 
Davis (1996) considered the evolutionary origins of empathy and concluded that "affective responsivity [EE] may have evolved as a mechanism for producing self-sacrificing behavior, while role-taking [CE] might have evolved to allow more successful competition with one's primate peers" (p. 45). CE appears to be adaptive because it underpins sophisticated verbal and nonverbal communication, Machiavellian intelligence, general social expertise, and parenting skills. EE provides a basis for social bonding, parentoffspring bonding, helping behavior, and group cohesion. I suggested that it is functional for a human to be able to use CE without EE, to use EE without or before CE, and to use CE and EE in an integrated way (Smith, 2006). (For example, exploiting, deceiving, and harming other people may simultaneously require the use of $\mathrm{CE}$ and the inhibition of EE. Parental responses to distressed children may be motivated by direct EE that precedes CE. General prosocial behavior may be facilitated by balanced empathy.) These empathic options are available if CE and EE are separable, complementary systems. With this relationship, the two empathic capacities can influence, balance, and regulate each other while retaining a significant degree of independence. The same range of empathic options is not available if CE and EE are, for example, inseparable or if one system is dependent on the other. It seems likely that separability of CE and EE was selected for during hominid evolution and that this relationship is evolutionarily stable.

One way to test the hypothesis that CE and EE are separable systems is to look for the potential empathy disorders that are consistent with such a relationship. I predicted the existence of four developmental empathy disorders: (a) CE deficit disorder (low CE ability combined with high EE sensitivity), (b) EE deficit disorder (low EE sensitivity combined with high CE ability), (c) general empathy deficit disorder (low CE ability and low EE sensitivity), and (d) general empathy surfeit disorder (high CE ability and high EE sensitivity). I hypothesized that these four disorders tend to be part of (1) autism, (2) antisocial personality disorder, (3) schizoid personality disorder (and some cases of autism spectrum disorder), and (4) Williams syndrome, respectively. Williams syndrome is a neurodevelopmental disorder characterized by intellectual deficits, linguistic skill, hypersociability, and concern for others. People with schizoid personality disorder are solitary individuals who unintentionally disregard social norms and appear to lack empathy. Schizoid personality disorder, unlike schizotypal personality disorder, is not closely related to the positive symptoms of schizophrenia and can resemble Asperger syndrome.

According to this approach, autism and antisocial personality disorder are opposite empathy imbalance disorders. This deduction partially corresponds to recent interpretations of the empirical literature. HansmanWijnands and Hummelen (2006) highlighted the fact that empathy deficit is a core symptom of both autism and antisocial personality disorder. They suggested that autism involves a CE deficit but antisocial personality disorder involves an EE deficit. Similarly, Robbins and Jack (2006) concluded that "as far as lack of the two kinds of empathy is concerned, autism and psychopathy [antisocial personality disorder] are complementary disorders" (p. 68). Blair (2005) argued that individuals with autism have deficits in CE but less clear deficits in EE. He also argued that individuals with antisocial personality disorder have a deficit in a specific form of EE (i.e., responsiveness to others' distress cues) but no deficit in CE. However, in Smith (2006), the predicted EE 
deficit in antisocial personality disorder is not specific to distress cues but includes reduced sensitivity to the happiness of others. Furthermore, in my framework, a lack of one kind of empathy can be accompanied by an excess of the other kind of empathy. I also suggested that the CE and EE systems of males have greater separability than those of females and that empathy imbalance disorders are thus more likely to develop in males than in females. (Greater separability of the empathy systems would give males more scope to use CE in an emotionally detached and competitive way. Lesser separability of the empathy systems might facilitate nurturing and social bonding.)

There is evidence that people with antisocial personality disorder have strong CE ability (Blair et al., 1996; Richell et al., 2003) but low sensitivity to others' distress (Blair, Jones, Clark, \& Smith, 1997) and happiness (Deeley et al., 2006). Recent research also seems to confirm that a minority of people diagnosed with Asperger syndrome are callous and have both a CE deficit and a substantial EE deficit (Rogers, Viding, Blair, Frith, \& Happe, 2006). In the next section of this article, I elaborate on the EIH of autism and focus on the counterintuitive possibility that most people with autism have a heightened capacity for direct EE.

\section{Elaboration of the Hypothesis}

There is a consensus that genetic and neurodevelopmental factors play a significant role in the etiology of autism (e.g., Frith \& Hill, 2004). Although psychogenic explanations of autism have been rejected, psychological theory remains important. It is used to describe and understand the behavioral development of people with autism (e.g., Charman, 2004). Autism researchers have focused on theory of mind deficits, executive dysfunction, weak central coherence, attentional problems, and affective impairments (for reviews, see Hill \& Frith, 2004; Rajendran \& Mitchell, 2007; Sigman \& Capps, 1997). The EIH of autism may be relevant to all of these theories, but it obviously connects to the first one: According to the theory of mind hypothesis, children with autism struggle to develop the CE ability that other humans use automatically in everyday life.

\section{The Theory of Mind Hypothesis and the EIH}

There is evidence that people with autism do not easily identify the following phenomena in social situations: false belief, second-order belief, complex causes of emotion, irony, pretence, metaphor, deception, faux pas, white lies, and double bluff (e.g., see Baron-Cohen, 2000; Happe, 1994; Hill \& Frith, 2004). These are facets of CE that most individuals intuitively digest as they develop, although behavior analysts argue that specific learning histories are involved (e.g., McHugh, Barnes-Holmes, \& Barnes-Holmes, 2004; Rehfeldt, Dillen, Ziomek, \& Kowalchuk, 2007). The gestural patterns of children with autism are also consistent with the theory of mind hypothesis (Baron-Cohen, 1995). Happe (1994) highlighted the power of the theory of mind hypothesis and the methodological diversity of the studies that have investigated it. Baron-Cohen (1995) reviewed theory of mind research and described people with autism as "mindblind." He viewed mindblindness as a core deficit in autism, and "it is now widely accepted that individuals with autism are impaired in the intuitive understanding that people have mental states" (Hill 
\& Frith, 2004, p. 6). Nevertheless, the theory of mind hypothesis continues to be criticized. Theory of mind deficits are not unique to autism; Gernsbacher and Frymiare (2005) argued that performance on standard theory of mind tasks is determined by linguistic ability. However, a recent study of theory of mind in children with autism and children with specific language impairment used a nonverbal method and provided further evidence of a CE deficit in autism (Colle, Baron-Cohen, \& Hill, 2007).

Baron-Cohen (2002) complemented the theory of mind hypothesis by proposing the extreme-male-brain theory of autism. According to this account, males tend to have higher systemizing ability but lower empathizing ability than females. (Systemizing is the drive to examine and construct a range of rule-governed systems.) Autism is much more common in males than in females and may be an extreme form of the male brain. Questionnaire data appear to confirm that people with autism are weak empathizers but strong systemizers (Baron-Cohen, Richler, Bisarya, Gurunathan, \& Wheelwright, 2004). The EIH and the extreme-male-brain theory both incorporate the theory of mind hypothesis, but the concept of empathic imbalance appears to be incompatible with the extreme-male-brain theory. Although Baron-Cohen and Wheelwright (2004) presented a two-component model of empathy (a cognitive component and an emotional component represented pictorially by two overlapping circles), the extreme-male-brain theory groups CE and EE as a single dimension. In Baron-Cohen's theory, the male brain is not adept at empathizing (CE and EE combined), whereas in the EIH, males are at greater risk than females of lifelong empathic imbalance.

The extreme-male-brain theory continues the historical view that people with autism lack EE. Frith (1989) wrote that "the most general description of social impairment in Autism is lack of empathy. Autistic people are noted for their indifference to other people's distress, their inability to offer comfort, even to receive comfort themselves" (p. 154). Yirmiya, Sigman, Kasari, and Mundy (1992) noted that "one of the most striking characteristics of autistic individuals appears to be their inability to share emotional states with others" (p. 150). Hobson (1993) argued that children with autism have a "seriously impoverished" (p. 194) sense of emotional engagement with other people. The EIH of autism is not necessarily incompatible with these descriptions, and I will argue that, in terms of behavioral signs, an EE surfeit in the context of autism could sometimes mimic an EE deficit. In other words, children with autism may find it difficult to engage emotionally with others because their capacity for EE is excessive and not complemented by commensurate CE.

\section{Characteristics of CE Deficit Disorder}

What would be the psychological characteristics of individuals with low CE ability but high EE sensitivity? Such individuals would have communication problems and a reduced tendency to understand others' behavior in mentalstate terms. They would have a strong capacity for direct EE but a reduced capacity for indirect EE. They might sometimes experience empathic concern but lack the CE needed to channel this concern into flexible prosocial behavior. I predicted that people with CE deficit disorder would also spontaneously develop ways of limiting the attention they pay to the emotions of others (Smith, 2006). I suggested that their sense of self would easily be permeated by other people's emotions and that this could be a confusing and aversive 
experience. People with CE deficit disorder might particularly enjoy the company of happy people who behave in consistent and predictable ways.

In the general population, EE sensitivity is positively correlated with automatic mimicry of facial expressions (Sonnby-Borgstrom, 2002; SonnbyBorgstrom, Jonsson, \& Svensson, 2003). Thus, although people with CE deficit disorder may avoid attending to social stimuli, when they do actively attend to facial expressions they might show an unusually high degree of automatic mimicry.

Another prediction about CE deficit disorder stems from neuroimaging research on gustatory empathy. People activate regions of their brains involved in gustation (e.g., the anterior insula) when they observe other people's facial expressions of gustatory emotion (Jabbi, Swart, \& Keysers, 2007). Such activation of the gustatory cortex appears to be positively correlated with an individual's susceptibility to emotional contagion and personal distress (Jabbi et al., 2007). Hence, people with CE deficit disorder can be expected to show heightened neural responsiveness to the gustatory pleasure of others.

The concept of this disorder pertains to a question posed by Whiten (1997): "If [nonhuman] primates lack a theory of mind, yet are so socially expert, why need mindblind [autistic] people be so severely constrained in their social abilities?" (p. 155). The EIH of autism suggests one possible answer: Perhaps people with autism are severely affected because they have EE-dominated empathic imbalance, and this imbalance is more disabling than a general empathy deficit. Sigman and Capps (1997) noted that "their behavior suggests that autistic children lack either an interest, ability, or willingness to read the facial expressions of others" (p. 48). It is the possibility that people with autism are sometimes unwilling to attend to the facial expressions of others that is particularly relevant to the EIH. Do children with autism avoid attending to salient features of the social world in an attempt to prevent empathic overarousal, personal distress, and confusion?

\section{Autistic Behavior as an Adaptive Response to Empathic Imbalance}

My suggestion is that children with autism spontaneously develop a persistent cognitive-behavioral style (variously interpreted as weak central cohesion, executive dysfunction, or high systemizing ability) to cope with their empathic imbalance and to protect themselves from others' emotions. According to this view, autistic behavior can be an attempt to hone or deploy this cognitive-behavioral style. Avoidance behavior, obsessive interests, and insistence on routines may regulate the stress that stems from living among people whose behavior is difficult to comprehend but whose emotions are all too readily sensed. Low CE ability may reduce the salience of social stimuli and render the social world unpredictable and confusing. High EE sensitivity may compound this and act as a deterrent to attending to the social world. In normal development, people can use CE to regulate and resolve their EE responses; people with autism may try to control and narrow their attention in an attempt to regulate EE.

\section{Attentional Avoidance of Empathic Overarousal}

People with relatively low ability to regulate their emotions can be susceptible to empathic overarousal, and it seems that personal distress 
is caused by such overarousal (Decety \& Lamm, 2006; Eisenberg, 2000). Hoffman (2000) conceived of empathic overarousal as "an involuntary process that occurs when an observer's empathic distress becomes so painful and intolerable that it is transformed into an intense feeling of personal distress, which may move the person out of the empathic mode entirely" (p. 198). If complementarity of the CE and EE systems has been selected for during evolution, then disruption to the neural basis of the CE system could be accompanied by disinhibition of the EE system in both development and on-line processing. People with CE deficit disorder would thus be particularly susceptible to parallel affect and personal distress, without necessarily being conscious of the empathic origin of such feelings. In balanced empathy, CE provides crucial top-down processing that harnesses EE (Decety \& Lamm, 2006). For example, psychotherapists, compared with matched controls, appear to have superior CE ability and a lower susceptibility to personal distress (Hassenstab, Dziobek, Rogers, Wolf, \& Convit, 2007). Clinicians have observed that people with autism can be very distressed by others' emotions (e.g., Attwood, 1993), and I propose that this distress is caused by empathic overarousal. On the basis of the EIH, one might predict that people with autism would be more willing to pay attention to calm, happy people than to distressed or angry people. Exuberant positive emotion in others may also sometimes cause confusion and an uncomfortable degree of empathic arousal in children with autism. Indeed, there is evidence that children with autism, unlike control participants, respond avoidantly to praise by looking away or turning away from the people who are praising them (Kasari, Sigman, Baumgartner, \& Stipek, 1993).

Eye-tracking studies have demonstrated that the visual fixation patterns of people with autism in social situations differ from normal patterns (for an overview, see Klin, Jones, Schultz, \& Volkmar, 2004). People with autism do not seem to attend spontaneously to salient features of the social world in the way that most people do. It is possible that this reflects an attentional style that limits empathic arousal. Intriguingly, an adolescent with Asperger syndrome made the following comment on making eye contact with others: "You always feel as if the eyes are actually burning into you.... You can either look between their eyes or you can look at the mouth and you don't feel as if they are actually burning right into you" (Landsman, 2003). Gernsbacher and Frymiare (2005) provided several similar examples of people with autism reporting that it is painful for them to make eye contact because of the emotional significance of the eyes. One study found that "individuals with autism, relative to controls, focused twice as much time on the mouth region of faces and 2.5 times less on the eye region of faces when viewing dynamic social scenes" (Klin et al., 2004, p. 130). Recent psychophysiological research (Kylliainen \& Hietanen, 2006) is also consistent with the opinion that people with autism avoid eye contact with others in order to decrease arousal. Similarly, Dalton et al. (2005) reported evidence of an intense emotional response in individuals with autism associated with direct gaze. Dalton et al. proposed that "face-processing deficits in autism arise from hyperactivation in the central circuitry of emotion that produces heightened sensitivity to social stimuli" (p. 524). 


\section{The Motivational Conflict Hypothesis}

Tinbergen and Tinbergen (1983) observed the behavior of children with autism and perceived approach-avoidance conflict. As Hinde (1995) explained, the Tinbergens believed that "a conflict between hyperanxiety and sociality, comparable in principle to the conflicts Niko Tinbergen had studied in sticklebacks and gulls, was involved. They suggested that when the conflict becomes severe, the child withdraws and future socialization is severely hampered" (p. 101). The Tinbergens' work on autism has largely been dismissed or ignored by leading researchers (Kruuk, 2003; see Seifert, 1990, for a more favorable appraisal). Nevertheless, the motivational conflict hypothesis can be isolated from the Tinbergens' views on treating autism and their confrontational writing. Furthermore, Richer independently developed a similar ethological hypothesis (see Richer, 2001a, for a review). He described the social behavior of children with autism in terms of avoidance-dominated motivational conflict.

This ethological approach contrasts with the theory of mind account. Hinde (1991) argued that the conflict hypothesis is compatible with the theory of mind hypothesis, but Archer (1992) concluded that the two approaches may be difficult to integrate. The EIH of autism potentially integrates the two hypotheses. It seems likely that EE-dominated empathic imbalance would generate motivational conflict. People with CE deficit disorder might have a desire to form empathic connections, share positive emotion, and help others, but without normal CE to regulate their EE, such people would be vulnerable to empathic overarousal, confusion, frustration, and personal distress. Hence, if the EIH of autism is correct, one might expect children with autism to have deeply ambivalent feelings about social interaction.

Richer (1976) observed 8 children with classic autism and 8 children with mental retardation in an outdoor playground. He also observed a group of younger, typically developing children. Richer found that the children with autism had a lower threshold for flight behavior and behaved in ways that reduced the likelihood of social encounters. The children with autism scored significantly higher for various behaviors, such as lowering the head over the chest, facing the wall, or spending time on the periphery. Richer concluded that children with autism are not indifferent to others and tend actively to avoid social encounters. However, when Buitelaar, van Engeland, de Kogel, de Vries, and van Hoof (1991) measured the social behavior of children with autism in a playroom and made use of principal components analysis, they found little evidence to support Richer's hypothesis. Richer (2001a) argued that their conclusions were flawed for several reasons (e.g., children with autism would exhibit conflict behavior, rather than pure avoidance behavior, in a confined playroom).

Tinbergen and Tinbergen (1983) perceived the avoidance of social proximity as "a thing to which they [children with autism] give constant priority" (p. 67). The Tinbergens observed subtle signs of this, "such as turning away without actually moving away, turning the head sideways or letting the head hang, or even merely looking away with the eyes only ..., or looking 'blank,' or even closing the eyes" (p. 67). According to the EIH, these patterns of behavior can be an attempt to limit empathic arousal.

In balanced empathy, it is important to be able to distinguish between one's own emotions and those of others (Decety \& Lamm, 2006). The sense of self of people with autism, in contrast, might easily be overpowered by 
intense empathic connections to others. The result might be that avoidance of social proximity would become the default coping mechanism for some individuals with autism. One person with high-functioning autism has described "instinctive attempts to correct a feeling of having been 'engulfed'" (Williams, 1996, p. 126). She explained that "when my sense of 'existence of other' . . . became too intense, I felt . . . swept up and lost in it but also suffocated" (p. 126). Stereotypic patterns in autism might sometimes be an attempt to prevent or disengage from empathic connections. For Williams, "repetitive self-tapping seemed to consolidate my own body separateness" (p. 126). EEdominated empathic imbalance potentially explains the inadequate integration of self and other that Richer (2001b) perceived in autism. Without the CE-based ability to understand two different perspectives simultaneously, the emotions of people with autism may all too easily become entangled with the emotions of others. Ramachandran (2003) suggested that children with autism "engage in self-stimulation to enhance their sense of being a self anchored in a body" (p. 125). There is also evidence that children with autism use self-stimulation to reduce excessive activity of the sympathetic nervous system (Hirstein, Iversen, \& Ramachandran, 2001). Empathic imbalance could contribute to this self-stimulatory behavior.

\section{Executive Function, Central Coherence, and Systemizing}

An alternative answer to Whiten's question (mentioned earlier) is that people with autism are constrained in their social abilities because of executive dysfunction, weak central coherence, or a strong preference for systemizing. Executive function refers to high-level planning, impulse control, and behavioral flexibility. Theorists interested in executive dysfunction thus focus on the stereotypic behaviors, attentional narrowing, and planning problems associated with autism (see Rajendran \& Mitchell, 2007). However, I have already suggested that some of these features are explicable in terms of EE-dominated empathic imbalance. In addition, it is not clear to what extent tests of executive function can be tests of the CE-based ability to monitor one's own mental states (Baron-Cohen, 1995); it has been argued that CE ability underlies executive functioning (Perner \& Lang, 2000). Executive dysfunction is found in a variety of children with developmental delays and may not be a necessary feature of autism (Baron-Cohen, 2003).

Central coherence refers to the ability to integrate fragments of information into a meaningful whole (Frith, 1989). Theorists interested in weak central coherence have thus suggested that people with autism attend excessively to local detail and struggle to perceive holistic patterns. However, there is evidence of central coherence in autism (e.g., Caron, Mottron, Berthiaume, \& Dawson, 2006; Garner \& Hamilton, 2001), and Baron-Cohen (2002, 2003) suggested that systemizing is facilitated by an initial preference for detail-focused processing. It is possible that high systemizing ability in autism can be explained in terms of empathic imbalance: People who find the social world difficult to understand are likely to develop an interest in predictable and controllable systems. Furthermore, attending to the details of systems may facilitate avoidance of EE. Baron-Cohen (2003) wrote that "the spotlight of attention on one tiny variable becomes all that matters, and they [people with autism] might not notice if a person stood next to them with tears rolling down their cheeks" (p. 133). So, according to the extreme- 
male-brain theory, people with autism may ignore the emotions of others because they are fascinated by the details of a system. But according to the EIH, people with autism may sometimes attend to such details in order to insulate themselves from the emotionality of others. Decety and Lamm (2006) pointed out that distractive strategies may be important for humans if the cost of empathizing is excessive. As Decety and Lamm explained, such strategies reduce the availability of attentional resources for perceiving and processing stimuli that can trigger EE. Systemizing, such as concentrating on a mathematical idea or an obscure set of facts, could function as an excellent distractive strategy.

\section{The Amygdala and the Intense World Hypothesis}

The amygdala plays an important role in EE, and dysfunction of this part of the limbic system has been implicated in autism (Baron-Cohen et al., 2000). There are cortical and subcortical pathways that connect the sensory thalamus to the amygdala (LeDoux \& Phelps, 2000), and there is evidence that the amygdala may be hyperresponsive in autism (Dalton et al., 2005). The neural foundation of an EE surfeit could be a hyperresponsive amygdala activated by the subcortical pathway and insufficiently down-regulated by cortical activity (due to CE deficits).

Markram, Rinaldi, and Markram (2007) introduced the "intense world" hypothesis of autism and paid particular attention to the role of the amygdala. They argued, on the basis of neurophysiological findings in a rodent model of autism, that the disorder involves hyperreactivity and hyperplasticity of local neuronal circuits. At the psychological level, Markram et al. thus viewed hyperfunctionality as the hallmark of autism. The intense world hypothesis is similar to the EIH because Markram et al. suggested that this hyperfunctionality includes hypersensitive EE. They proposed that "impaired social interactions and withdrawal may not be the result of a lack of compassion ... or lack of emotionality, but quite to the contrary a result of an intensely if not painfully aversively perceived environment" (p. 90). Markram et al. argued that "the amygdala in the autistic individual may be hyper-reactive which leads to rapid excessive responses to socio-emotional stimuli" (p. 91).

In this section, I have thus suggested that a variety of theoretical perspectives and research findings are highly compatible with the EIH. In the next section, I review some specific evidence for the hypothesis.

\section{Evidence of Intact or Excessive EE in Autism}

\section{Empirical Evidence}

Perhaps the earliest evidence of high EE sensitivity in autism comes from a laboratory study by Capps, Kasari, Yirmiya, and Sigman (1993). Capps et al. analyzed the facial affect of children with high-functioning autism while the participants watched "videotaped vignettes designed to elicit empathy" (p. 477). Each vignette featured a child protagonist experiencing happiness, pride, sadness, fear, or anger. The 16 participants with autism (mean age = 146 months) were compared with 19 typically developing children. Capps et al. hypothesized that the children with autism would display less positive 
affect than the comparison children. In fact, they found that the children with autism showed considerably more positive affect than the comparison children. While viewing the vignettes, the children with autism also showed significantly more concentration than the comparison children. The emotional responses of the children with autism were found to be appropriate to the situation of the protagonist in the vignettes. The children with autism displayed concentration or neutrality but minimal positive or negative affect while viewing the vignettes that featured negative emotion.

These results seem consistent with the EIH of autism. In contrast to the researchers' prediction, the children with autism in this study appeared to display significantly more EE than the typically developing children. However, the increased display of concentration in the children with autism was consistent with the researchers' predictions. Capps et al. (1993) had hypothesized that "the empathy paradigm would be more taxing for autistic than for normal children and that this would be manifested in facial expression of concentration or effort" (p. 477). Yet the paradigm was not so taxing that the children with autism were less emotionally empathic than the typically developing children. It is possible that the amount of concentration reflected the intensity of the empathic connections. The data also seem consistent with the hypothesis that people with autism may be more willing to empathize with happy people than with distressed people. Capps et al. concluded that "autistic subjects' facial expressiveness suggests that they do respond to others' emotions, yet they may have difficulty appropriating this response" (p. 482).

Compelling evidence of an EE surfeit in autism also comes from a recent study of automatic mimicry of facial expressions. Magnee, de Gelder, van Engeland, and Kemner (2007) used facial electromyography to measure subtle emotional responses in 13 young men with high-functioning autism or Asperger syndrome and 13 controls (healthy men matched for age and IQ). The participants were presented with pictures of happy and fearful faces and instructed to judge the sex of each face. The researchers were surprised to find that the participants with autism spectrum disorders showed significantly heightened electromyographic responsiveness both to happy and to fearful faces.

This result contrasts with a previous study that found deficits in automatic mimicry of emotional expressions in autism (McIntosh, ReichmannDecker, Winkielman, \& Wilbarger, 2006). Magnee et al. (2007) suggested that the crucial difference between the two studies was that McIntosh et al. did not set their participants an active task requiring careful attention to the faces. McIntosh et al. simply instructed their participants to "watch the pictures as they appear on the screen" (p. 297).

There is evidence that rapid facial reactions measured by electromyography are genuinely emotional phenomena (Moody, McIntosh, Mann, \& Weisser, 2007) and correlate with self-reported EE (Sonnby-Borgstrom, 2002). The data presented by McIntosh et al. (2006) are consistent with the hypothesis that people with autism may not actively attend to emotional expressions in order to minimize empathic arousal. However, the data presented by Magnee et al. (2007) provide evidence that the underlying capacity for EE in autism is not just intact but excessive.

Another way to study EE sensitivity is to measure electrodermal responses to relevant stimuli. Blair (1999) found that children with autism showed appropriate psychophysiological responses to images of distressed people. 
Importantly for the EIH, "two of the children with autism tested placed their hands in front of their eyes when a distress cue picture was presented to them and refused to look at it" (p. 483). Clearly, people with autism are sometimes reluctant to attend to emotional expressions, and it is unlikely that people with low EE sensitivity would find images of distress so aversive.

EE facilitates moral development (e.g., Hoffman, 2000), and there is evidence that children with autism can distinguish between moral and conventional rules: They appear to understand that it is unacceptable to disregard rules that prevent human suffering but potentially acceptable to disregard rules that are merely conventions (Blair, 1996; see also Grant, Boucher, Riggs, \& Grayson, 2005). This ability arguably indicates a significant degree of EE sensitivity in people with autism. That people with autism often feel contrite about inadvertently upsetting other people (e.g., see Baron-Cohen \& Wheelwright, 2004) is also consistent with the EIH.

Questionnaires can be used to probe empathy in people with highfunctioning autism. Rogers, Dziobek, Hassenstab, Wolf, and Convit (2007) asked 21 adults with Asperger syndrome and 21 matched controls to complete the Interpersonal Reactivity Index. This instrument includes items designed to tap empathic concern and items designed to tap personal distress. The two groups of participants scored similarly for empathic concern, but the participants with Asperger syndrome scored significantly higher than the controls on the personal distress scale. The latter result indicates that people with Asperger syndrome may be particularly susceptible to empathic overarousal. Indeed, Rogers et al. acknowledged that their findings could be interpreted as evidence of greater empathy in the participants with Asperger syndrome. The researchers also pointed out that people with the syndrome have a general tendency to be anxious and that this may contribute to personal distress. These two interpretations are not mutually exclusive if empathic imbalance is a cause of anxiety in autism.

If the EIH is correct, then the emotional status of other people can be expected to influence the behavior of children with autism. Indeed, displaying positive emotion in consistent and predictable ways could be one of the most therapeutic techniques that caregivers might employ. It might reduce the frequency of avoidant, stereotypic, or challenging behavior in people with autism. A preliminary study (Merges, 2003) of 3 children with autism provided evidence that this may be the case. Merges exposed the children to two emotional contagion conditions (a positive emotion condition and a neutral emotion condition). The children engaged in fewer challenging behaviors during the positive emotion contagion condition. Merges concluded that children with autism may be directly impacted by the emotions of those around them. This study may merit replication with the addition of a control group of nonautistic children who exhibit challenging behavior.

\section{Narratives of Practitioners, Caregivers, and People With Autism}

A number of autistic narratives allude to excessive EE and complement the empirical literature. Caldwell (2006), an experienced autism practitioner, has independently proposed an idea that is similar to the EIH. She has argued that many people with autism are sensitive to the emotions of others to a painful and excessive degree. She suggested that people with autism thus learn to suppress their EE. Otter and Masefield (2001), drawing on their experience as 
specialist teachers with an interest in Facilitated Communication, observed that "some people with autism seem to be highly sensitive to non-verbal signals of mood and intention, even though they may not always know . . . how to respond appropriately to them" (p. 172). They portrayed individuals with autism as confused about the facilitator's mental states but nevertheless as sensitive to the facilitator's "vibes."

Hughes (2003) wrote about his son with autism, Walker. According to Hughes, Walker's "supersensitive emotional barometer registered the true emotional pressure in the air, no matter how hard we tried to mask it" (p. 130). The grandmother of a boy with autism named Julian perceived her grandson as "a sensitive child with his own quirks and oddities that he was entitled to, picking up negative and positive vibrations around him like most children, only in his case more so" (Wheatley, 2005, p. 30). Kaufman (1994) noted that his son with autism "seemed almost telepathic in his ability to detect the discomforts and moods of those around him" and that he "moved away from people who appeared distressed by his actions" (p. 81). Kaufman suggested that it is therapeutic for children with autism if caregivers can change their emotional attitude toward autistic behavior from one of distress to one of acceptance.

O’Neill (1999), a writer with autism, said, "I am both hyper-emotional and hyper-sensory. To me, everything is acutely heightened, and I also have extremely intense emotions" (p. 24). She added that "it is highly difficult to hide anything from them [people with autism]. They detect the emotions of other people. Often they reflect the emotions of others, so care must be taken to work on keeping the home atmosphere positive, loving, and balanced" (p. 42). McKean (1994), another writer with autism, explained that he rarely knows what anyone is thinking but that "concurrent emotions are very common" (p. 54). He wrote that it is like there is "a sequence written on the eyes of the other person that tells my brain and my emotions exactly how they should be feeling at that point. These feelings are inevitably always what that other person happens to be feeling" (p. 54). McKean suggested that in autism, this capacity is "a rather cruel practical joke of nature" (p. 54).

Williams (1998), who has autism, wrote about merging with other people and "an intense, uncontrollable empathy" (p. 59). She recalled that in a supermarket she "physically felt the pain when someone banged themselves" (p. 59). She described frightening experiences in which other people swept her selfhood away "as easily as cobwebs with a duster" (p. 59).

Sainsbury (n.d.), a woman with Asperger syndrome, wrote, "I have seen photos of children undergoing holding therapy and I can't bear to look at them for more than a few seconds, because the pain and terror on their faces is so strong." Finally, according to one support group, "persons on the autistic spectrum are far more empathetic than most, but the intense sensitivity of the empathetic feeling that they do have for others makes them withdraw, as they do not have the capacity to communicate this empathy" (Ontario Adult Autism Research and Support Network, 2007).

\section{Evidence Apparently Against the Hypothesis}

Sigman, Kasari, Kwon, and Yirmiya (1992) studied responses to the negative emotions of others by 30 children with classic autism (mean age $=42.4$ months). The control participants were 30 nonautistic children with mental retardation and 30 typically developing children with a mental age 
equivalent to the other children's. Sigman et al. found that both sets of nonautistic children, unlike the children with autism, were "very attentive to adults showing distress, fear, and discomfort" (p. 804). The children with autism seemed to have significantly less EE than the other children. In one of the experimental conditions in this study, the children were shown how to use a wooden toy and hammer. The adult (a parent or experimenter) pretended to hurt herself and displayed facial and vocal (nonverbal) expressions of distress. The analysis showed that during the distress displays, the children with autism looked at the toy far more than the other children looked at the toy. Although this study seems to support the hypothesis that children with autism have an EE deficit, it can also be interpreted as supporting the EIH. The fact that the children with autism attended to the toy during the display of distress is consistent with the hypothesis that such children use attentional avoidance to prevent empathic overarousal.

Yirmiya et al. (1992) found that older children with high-functioning autism scored lower on a measure of empathy than typically developing children. However, the researchers were surprised by how well the individuals with autism performed. The measure of empathy used in that study included the ability to label one's own and others' emotions and was not just a measure of EE sensitivity.

Two recent studies do not appear to support the EIH. Scambler, Hepburn, Rutherford, Wehner, and Rogers (2007) found that young children with autism displayed EE less frequently than other children. This reduced responsiveness could not be explained by a failure to look at the experimenters' emotional displays. (For example, 19 out of 26 children with autism attended to an episode in which the experimenter banged her thumb, but only 2 of those children responded with observable emotional contagion.) Sigman, Dissanayake, Corona, and Espinosa (2003) found no evidence that a videotape of a crying baby was either arousing or aversive to young children with autism. These studies do not rule out the possibility that people with autism use subtle attentional patterns or covert distractive strategies that limit empathic arousal. It is also conceivable that people with autism sometimes refrain from displaying facial affect in order to restrict EE. Darwin (1872/1965) famously pointed out that "the free expression by outward signs of an emotion intensifies it" but that "the repression, as far as this is possible, of all outward signs softens our emotions” (p. 365). If people with autism inhabit an intense subjective world, they may spontaneously exploit Darwin's insight. (The great advantage of the electromyographic research described earlier is that it measures facial changes that usually elude human observation.)

Returning to questionnaire research, Baron-Cohen et al. (2004) reported that people with high-functioning autism or Asperger syndrome scored significantly lower on the Empathy Quotient than matched controls. However, most of the items in this questionnaire seem designed to tap CE and indirect EE. Only a small proportion of the items seem likely to tap direct EE. People with low CE ability but high EE sensitivity would probably not score high on this questionnaire. Furthermore, could subtle CE deficits cause adults with autism to misjudge their capacity for empathy when completing the Empathy Quotient? Baron-Cohen and Wheelwright (2004) were confident that any such misjudgment would only cause an overestimate of the person's true Empathy Quotient score. However, people with EE-dominated empathic imbalance may share others' emotions unwittingly. In addition, some people who have learned 
to avoid EE may mistakenly believe that they lack the capacity for EE. There are thus reasons to believe that the Empathy Quotient could underestimate the EE sensitivity of people with autism.

\section{Testing the Hypothesis}

Although I believe that autism is the best place to look for the existence of CE deficit disorder, it seems clear that some people with a general empathy deficit receive autism spectrum diagnoses (see Rogers et al., 2006). Past research is thus likely to have underestimated the mean EE sensitivity of the large subgroup of people with autism who seem to have CE deficit disorder. Ideally, studies testing the EIH of autism would exclude autistic participants with callous traits or try to distinguish them from other participants.

The pictorial emotional Stroop paradigm provides a basis for experimental exploration of the EIH. Ashwin, Wheelwright, and Baron-Cohen (2006) used this paradigm to study people with Asperger syndrome. Participants are presented with stimuli and instructed to name the color of each stimulus as quickly as possible. (The stimuli consist of pictures of faces that are overlaid with transparent colors. Ashwin et al. used faces with angry expressions and faces with neutral expressions.) The time taken to name the color (i.e., the response latency) is measured. Relative to neutral expressions, facial emotion may increase response latencies (i.e., an interference effect) or decrease response latencies (i.e., a facilitation effect). Emotional expressions that attract the participant's attention interfere with the task of naming the colors. Conversely, expressions that repel the participant's attention facilitate the naming task.

I have argued that people with autism find it abnormally painful to attend to expressions of negative emotion but potentially pleasant to attend to expressions of happiness. If the data from the participants with autism revealed a facilitation effect for angry faces relative to neutral faces, this would be consistent with the EIH. Ashwin et al. (2006) found that data from the control group revealed an interference effect for angry faces. In contrast, participants with Asperger syndrome showed shorter response latencies to angry faces than to neutral faces, but this hint of a facilitation effect was not statistically significant.

This study could be repeated using distressed faces, happy faces, and neutral faces as stimuli. I predict that distressed faces would significantly facilitate the task performance of participants with autism and that happy faces might interfere with their performance. However, a modification of the stimuli used in the pictorial emotional Stroop paradigm could provide a more potent method for exploring the EIH. Instead of overlaying the entire pictures with transparent colors, the eye color of facial images could be manipulated. The participants would be instructed to name the eye color in each stimulus. This modified paradigm would require the participant to attend to the most emotionally salient region of the face to perform the naming task. This might sharpen EEbased interference or facilitation effects. The EIH would be supported by data showing a pattern of interference or facilitation effects in autism that would differ significantly from normal patterns and even more from the responses associated with antisocial personality disorder. More specifically, I predict that participants with autism in the modified paradigm would show abnormally long response latencies to distressed faces and relatively short latencies to happy faces. Given that people with autism may find images of distressed people aversive, this research would not be ethically simple. 


\section{Conclusion}

The study of autism is probably the study of an empathy disorder. But what sort of empathy disorder? Any conclusion positing that most people with autism have a general empathy deficit does not seem justified. This article has outlined an account of autism as an empathy imbalance disorder. I have argued that people with autism tend to have low CE ability but high EE sensitivity. The behavior patterns that lead to a diagnosis of autism might be generated by this imbalance. There is evidence that seems consistent with the hypothesis that people with autism have low EE sensitivity, but there is growing evidence that supports the EIH. People with autism may use avoidant patterns of attention to restrict empathic arousal, and researchers should consider the possibility that an EE surfeit can mimic an EE deficit. The concept of an EE surfeit is consistent with a recurrent theme in the narratives of people with autism and their caregivers. The surfeit concept also relates well to the account of autism as an intense world syndrome characterized by hyperfunctionality and a hyperresponsive amygdala.

The EIH of autism builds on the theory of mind hypothesis and the motivational conflict hypothesis but departs from the extreme-male-brain theory. Baron-Cohen played a central role in establishing the theory of mind hypothesis, but his definition of empathizing seems tailored to the extrememale-brain theory of autism: If CE is the first stage in empathizing and EE (or empathic concern) is the second stage, then people with a CE deficit may almost inevitably be identified as weak empathizers. However, if CE and EE are separable systems, then either CE or EE can be the first empathic step. (It would be equally reasonable to define empathizing as the ability to share another's emotion and to respond to it with an appropriate belief about the other person's mental state.) The central proposal of this article has been that most people with autism have a capacity for EE that outstrips their CE ability in a problematic way. The EIH is a tentative addition to the array of theoretical searchlights that help illuminate autism.

\section{References}

ARCHER, J. (1992). Ethology and human development. Hemel Hempstead, England: Harvester Wheatsheaf.

ASHWIN, C., WHEELWRIGHT, S., \& BARON-COHEN, S. (2006). Attention bias to faces in Asperger syndrome: A pictorial emotion Stroop study. Psychological Medicine, 36, 835-843.

ATTWOOD, T. (1993). Why does Chris do that? Some suggestions regarding the cause and management of the unusual behaviour of children and adults with autism and Asperger Syndrome. London: National Autistic Society.

BARON-COHEN, S. (1995). Mindblindness: An essay on autism and theory of mind. Cambridge, MA: MIT Press.

BARON-COHEN, S. (2000). Theory of mind and autism: A fifteen year review. In S. Baron-Cohen, H. Tager-Flusberg, \& D. J. Cohen (Eds.), Understanding other minds: Perspectives from developmental cognitive neuroscience (pp. 3-20). Oxford, England: Oxford University Press.

BARON-COHEN, S. (2002). The extreme male brain theory of autism. Trends in Cognitive Sciences, 6, 248-254.

BARON-COHEN, S. (2003). The essential difference. London: Penguin. 
BARON-COHEN, S., RICHLER, J., BISARYA, D., GURUNATHAN, N., \& WHEELWRIGHT, S. (2004). The systemizing quotient: An investigation of adults with Asperger syndrome or high-functioning autism, and normal sex differences. In U. Frith \& E. L. Hill (Eds.), Autism: Mind and brain (pp. 161-186). Oxford, England: Oxford University Press.

BARON-COHEN, S., RING, H. A., BULLMORE, E. T., WHEELWRIGHT, S., ASHWIN, C., \& WILLIAMS, S. C. R. (2000). The amygdala theory of autism. Neuroscience and Biobehavioral Reviews, 24, 355-364

BARON-COHEN, S., \& WHEELWRIGHT, S. (2004). The empathy quotient:

An investigation of adults with Asperger syndrome or highfunctioning autism, and normal sex differences. Journal of Autism and Developmental Disorders, 34, 163-175.

BISCHOF-KOHLER, D. (1991). The development of empathy in infants. In M. Lamb \& H. Keller (Eds.), Infant development: Perspectives from Germanspeaking countries (pp. 245-273). Hillsdale, NJ: Erlbaum.

BLAIR, R. J. R. (1996). Brief report: Morality in the autistic child. Journal of Autism and Developmental Disorders, 26, 571-579.

BLAIR, R. J. R. (1999). Psychophysiological responsiveness to the distress of others in children with autism. Personality and Individual Differences, 26, 477-485.

BLAIR, R. J. R. (2005). Responding to the emotions of others: Dissociating forms of empathy through the study of typical and psychiatric populations. Consciousness and Cognition, 14, 698-718.

BLAIR, R. J. R., JONES, L., CLARK, F., \& SMITH, M. (1997). The psychopathic individual: A lack of responsiveness to distress cues? Psychophysiology, 34, 192-198.

BLAIR, J., SELLARS, C., STRICKLAND, I., CLARK, F., WILLIAMS, A., SMITH, M., ET AL. (1996). Theory of mind in the psychopath. The Journal of Forensic Psychiatry, 7, 15-25.

BUITELAAR, J. K., VAN ENGELAND, H., DE KOGEL, K. H., DE VRIES, H., \& VAN HOOFF, J. A. R. A. M. (1991). Differences in the structure of social behaviour of autistic children and non-autistic retarded controls. Journal of Child Psychology and Psychiatry, 32, 995-1015.

CALDWELL, P. (2006). Finding you finding me: Using intensive interaction to get in touch with people whose severe learning disabilities are combined with autistic spectrum disorder. London: Jessica Kingsley.

CAPPS, L., KASARI, C., YIRMIYA, N., \& SIGMAN, M. (1993). Parental perception of emotional expressiveness in children with autism. Journal of Consulting and Clinical Psychology, 61, 475-484.

CARON, M. J., MOTTRON, L., BERTHIAUME, C., \& DAWSON, M. (2006). Cognitive mechanisms, specificity and neural underpinnings of visuospatial peaks in autism. Brain, 129, 1789-1802.

CHARMAN, T. (2004). Why is joint attention a pivotal skill in autism? In U. Frith \& E. L. Hill (Eds.), Autism: Mind and brain (pp. 67-87). Oxford, England: Oxford University Press.

COLLE, L., BARON-COHEN, S., \& HILL, J. (2007). Do children with autism have a theory of mind? A non-verbal test of autism vs. specific language impairment. Journal of Autism and Developmental Disorders, 37, 716-723.

COOPER, J. E. (Ed.). (1994). Pocket guide to the ICD-10 classification of mental and behavioural disorders. Edinburgh, Scotland: Churchill Livingstone. 
DALTON, K. M., NACEWICZ, B. M., JOHNSTONE, T., SCHAEFER, H. S., GERNSBACHER, M. A., GOLDSMITH, H. H., ET AL. (2005). Gaze fixation and the neural circuitry of face processing in autism. Nature Neuroscience, 8 , 519-526.

DARWIN, C. (1965). The expression of the emotions in Man and animals. Chicago: The University of Chicago Press. (Original work published 1872)

DAVIS, M. (1996). Empathy: A social psychological approach. Boulder, CO: Westview Press.

DECETY, J., \& JACKSON, P. L. (2004). The functional architecture of human empathy. Behavioral and Cognitive Neuroscience Reviews, 3, 71-100.

DECETY, J., \& LAMM, C. (2006). Human empathy through the lens of social neuroscience. The Scientific World Journal, 6, 1146-1163.

DEELEY, Q., DALY, E., SURGULADZE, S., TUNSTALL, N., MEZEY, G., BEER, D., ET AL. (2006). Facial emotion processing in criminal psychopathy: Preliminary functional magnetic resonance imaging study. British Journal of Psychiatry, 189, 533-539.

DE VIGNEMONT, F., \& SINGER, T. (2006). The empathic brain: How, when and why? Trends in Cognitive Sciences, 10, 435-441.

EISENBERG, N. (2000). Empathy and sympathy. In M. Lewis \& J. M. HavilandJones (Eds.), Handbook of emotions (2nd ed., pp. 677-691). New York: Guilford Press.

EISENBERG, N., \& STRAYER, J. (1987). Critical issues in the study of empathy. In N. Eisenberg \& J. Strayer (Eds.), Empathy and its development (pp. 3-13). Cambridge, England: Cambridge University Press.

FRITH, U. (1989). Autism: Explaining the enigma. Oxford, England: Blackwell.

FRITH, U., \& HILL, E. L. (Eds.). (2004). Autism: Mind and brain. Oxford, England: Oxford University Press.

GARNER, I., \& HAMILTON, D. (2001). Evidence for central cohesion: Children with autism do experience visual illusions. In J. Richer \& S. Coates (Eds.), Autism: The search for coherence (pp. 75-85). London: Jessica Kingsley.

GERNSBACHER, M. A., \& FRYMIARE, J. L. (2005). Does the autistic brain lack core modules? Journal of Developmental and Learning Disorders, 9, 3-16.

GRANT, C. M., BOUCHER, J., RIGGS, K. J., \& GRAYSON, A. (2005). Moral understanding in children with autism. Autism, 9, 317-331.

HANSMAN-WIJNANDS, M. A., \& HUMMELEN, J. W. (2006). Differentiele diagnostiek van psychopathie en autismespectrumstoornissen bij volwassenen: Empathiegebrek als kernsymptoom [Differential diagnosis of psychopathy and autism spectrum disorders in adults: Empathic deficit as a core symptom]. Tijdschrift Voor Psychiatrie, 48, 627-636.

HAPPE, F. (1994). Autism: An introduction to psychological theory. London: UCL Press.

HASSENSTAB, J., DZIOBEK, I., ROGERS, K., WOLF, O. T., \& CONVIT, A. (2007). Knowing what others know, feeling what others feel: A controlled study of empathy in psychotherapists. The Journal of Nervous and Mental Disease, 195, 277-281.

HILL, E. L., \& FRITH, U. (2004). Understanding autism: Insights from mind and brain. In U. Frith \& E. L. Hill (Eds.), Autism: Mind and brain (pp. 1-20). Oxford, England: Oxford University Press.

HINDE, R. A. (1991). From animals to humans. In M. S. Dawkins, T. R. Halliday, \& R. Dawkins (Eds.), The Tinbergen legacy (pp. 31-39). London: Chapman \& Hall. 
HINDE, R. A. (1995). Konrad Lorenz (1903-89) and Nikolaas Tinbergen (1907-88). In R. Fuller (Ed.), Seven pioneers of psychology (pp. 75-105). London: Routledge.

HIRSTEIN, W., IVERSEN, P., \& RAMACHANDRAN, V. S. (2001). Autonomic responses of autistic children to people and objects. Proceedings of the Royal Society of London B, 268, 1883-1888.

HOBSON, R. P. (1993). Autism and the development of mind. Hove, England: Psychology Press.

HOFFMAN, M. L. (2000). Empathy and moral development: Implications for caring and justice. New York: Cambridge University Press.

HUGHES, R. (2003). Running with Walker: A memoir. London: Jessica Kingsley.

JABBI, M., SWART, M., \& KEYSERS, C. (2007). Empathy for positive and negative emotions in the gustatory cortex. NeuroImage, 34, 1744-1753.

KASARI, C., SIGMAN, M. D., BAUMGARTNER, P., \& STIPEK, D. J. (1993). Pride and mastery in children with autism. Journal of Child Psychology and Psychiatry, 34, 353-362.

KAUFMAN, B. N. (1994). Son rise: The miracle continues. Tiburon, CA: HJ Kramer. KLIN, A., JONES, W., SCHULTZ, R., \& VOLKMAR, F. (2004). The enactive mind, or from actions to cognition: Lessons from autism. In U. Frith \& E. L. Hill (Eds.), Autism: Mind and brain (pp. 127-159). Oxford, England: Oxford University Press.

KRUUK, H. (2003). Niko's nature: A life of Niko Tinbergen and his science of animal behaviour. Oxford, England: Oxford University Press.

KYLLIAINEN, A., \& HIETANEN, J. K. (2006). Skin conductance responses to another person's gaze in children with autism. Journal of Autism and Developmental Disorders, 36, 517-525.

LANDSMAN, F. (Producer). (2003, July 30). My family and autism [Television broadcast]. London: BBC 2.

LEDOUX, J. E., \& PHELPS, E. A. (2000). Emotional networks in the brain. In M. Lewis \& J. M. Haviland-Jones (Eds.), Handbook of emotions (2nd ed., pp. 157-172). New York: Guilford Press.

MAGNEE, M. J. C. M., DE GELDER, B., VAN ENGELAND, H., \& KEMNER, C. (2007). Facial electromyographic responses to emotional information from faces and voices in individuals with pervasive developmental disorder. Journal of Child Psychology and Psychiatry, 48, 1122-1130.

MARKRAM, H., RINALDI, T., \& MARKRAM, K. (2007). The intense world syndrome: An alternative hypothesis for autism. Frontiers in Neuroscience, 1, 77-96.

MCHUGH, L., BARNES-HOLMES, Y., \& BARNES-HOLMES, D. (2004). Perspectivetaking as relational responding: A developmental profile. The Psychological Record, 54, 115-144.

MCINTOSH, D. N., REICHMANN-DECKER, A., WINKIELMAN, P., \& WILBARGER, J. L. (2006). When the social mirror breaks: Deficits in automatic, but not voluntary, mimicry of emotional facial expressions in autism. Developmental Science, 9, 295-302.

MCKEAN, T. A. (1994). Soon will come the light: A view from inside the autism puzzle. Arlington, TX: Future Horizons.

MERGES, E. M. (2003). Emotion contagion in children with autism: The effect on affect and behavior [Abstract]. Dissertation Abstracts International, Section B, 64, 2930. 
MOODY, E. J., MCINTOSH, D. N., MANN, L. J., \& WEISSER, K. R. (2007). More than mere mimicry? The influence of emotion on rapid facial reactions to faces. Emotion, 7, 447-457.

O'NEILL, J. L. (1999). Through the eyes of aliens: A book about autistic people. London: Jessica Kingsley.

ONTARIO ADULT AUTISM RESEARCH AND SUPPORT NETWORK. (2007). News bulletin. Retrieved June 18, 2007, from http://www.ont-autism.uoguelph. ca/news-20060902.html

OTTER, L., \& MASEFIELD, E. (2001). Facilitated communication at the Chinnor Resource Unit: A journey. In J. Richer \& S. Coates (Eds.), Autism: The search for coherence (pp. 152-175). London: Jessica Kingsley.

PERNER, J., \& LANG, B. (2000). Theory of mind and executive function: Is there a developmental relationship? In S. Baron-Cohen, H. TagerFlusberg, \& D. J. Cohen (Eds.), Understanding other minds: Perspectives from developmental cognitive neuroscience (pp. 150-181). Oxford, England: Oxford University Press.

PINKER, S., \& BLOOM, P. (1992). Natural language and natural selection. In J. H. Barkow, L. Cosmides, \& J. Tooby (Eds.), The adapted mind: Evolutionary psychology and the generation of culture (pp. 451-493). New York: Oxford University Press.

PRESTON, S. D., \& DE WAAL, F. B. M. (2002). Empathy: Its ultimate and proximate bases. Behavioral and Brain Sciences, 25, 1-20.

RAJENDRAN, G., \& MITCHELL, P. (2007). Cognitive theories of autism. Developmental Review, 27, 224-260.

RAMACHANDRAN, V. S. (2003). The emerging mind. London: Profile Books. REHFELDT, R. A., DILLEN, J. E., ZIOMEK, M. M., \& KOWALCHUK, R. K. (2007). Assessing relational learning deficits in perspective-taking in children with high-functioning autism spectrum disorder. The Psychological Record, 57, 23-47.

RICHELL, R. A., MITCHELL, D. G. V., NEWMAN, C., LEONARD, A., BARONCOHEN, S., \& BLAIR, R. J. R. (2003). Theory of mind and psychopathy: Can psychopathic individuals read the "language of the eyes"? Neuropsychologia, 41, 523-526.

RICHER, J. (1976). The social-avoidance behaviour of autistic children. Animal Behaviour, 24, 898-906.

RICHER, J. (2001a). An ethological approach to autism: From evolutionary perspectives to treatment. In J. Richer \& S. Coates (Eds.), Autism: The search for coherence (pp. 22-35). London: Jessica Kingsley.

RICHER, J. (2001b). The insufficient integration of self and other in autism: Evolutionary and developmental perspectives. In J. Richer \& S. Coates (Eds.), Autism: The search for coherence (pp. 36-52). London: Jessica Kingsley.

ROBBINS, P., \& JACK, A. I. (2006). The phenomenal stance. Philosophical Studies, 127, 59-85.

ROGERS, J., VIDING, E., BLAIR R. J., FRITH, U., \& HAPPE, F. (2006). Autism spectrum disorder and psychopathy: Shared cognitive underpinnings or double hit? Psychological Medicine, 36, 1789-1798.

ROGERS, K., DZIOBEK, I., HASSENSTAB, J., WOLF, O. T., \& CONVIT, A. (2007). Who cares? Revisiting empathy in Asperger syndrome. Journal of Autism and Developmental Disorders, 37, 709-715. 
SAINSBURY, C. (n.d.). Holding therapy: An autistic perspective. Retrieved July 12, 2007, from http://www.nas.org.uk/nas/jsp/polopoly. jsp?d $=364 \& \mathrm{a}=2179$

SCAMBLER, D. J., HEPBURN, S., RUTHERFORD, M. D., WEHNER, E. A., \& ROGERS, S. J. (2007). Emotional responsivity in children with autism, children with other developmental disabilities, and children with typical development. Journal of Autism and Developmental Disorders, 37, 553-563.

SCOTTISH INTERCOLLEGIATE GUIDELINES NETWORK. (2007). Assessment, diagnosis and clinical interventions for children and young people with autism spectrum disorders. Edinburgh, Scotland: Author.

SEIFERT, C. D. (1990). Theories of autism. Lanham, MD: University Press of America.

SIGMAN, M., \& CAPPS, L. (1997). Children with autism: A developmental perspective. Cambridge, MA: Harvard University Press.

SIGMAN, M., DISSANAYAKE, C., CORONA, R., \& ESPINOSA, M. (2003). Social and cardiac responses of young children with autism. Autism, 7, 205-216.

SIGMAN, M. D., KASARI, C., KWON, J., \& YIRMIYA, N. (1992). Responses to the negative emotions of others by autistic, mentally retarded, and normal children. Child Development, 63, 796-807.

SLOBODA, J. A., \& JUSLIN, P. N. (2001). Psychological perspectives on music and emotion. In P. N. Juslin \& J. A. Sloboda (Eds.), Music and emotion: Theory and research (pp. 71-104). Oxford, England: Oxford University Press.

SMITH, A. (2006). Cognitive empathy and emotional empathy in human behavior and evolution. The Psychological Record, 56, 3-21.

SONNBY-BORGSTROM, M. (2002). Automatic mimicry reactions as related to differences in emotional empathy. Scandinavian Journal of Psychology, 43, 433-443.

SONNBY-BORGSTROM, M., JONSSON P., \& SVENSSON, O. (2003). Emotional empathy as related to mimicry reactions at different levels of information processing. Journal of Nonverbal Behavior, 27, 3-23.

TINBERGEN, N., \& TINBERGEN, E. A. (1983). "Autistic" children: New hope for a cure. London: George Allen and Unwin.

WHEATLEY, T. (2005). My sad is all gone: A family's triumph over violent autism. Lancaster, OH: Lucky Press.

WHITEN, A. (1997). The Machiavellian mindreader. In A. Whiten \& R. W. Byrne (Eds.), Machiavellian intelligence II: Extensions and evaluations (pp. 144-173). Cambridge, England: Cambridge University Press.

WILLIAMS, D. (1996). Autism: An inside-out approach. London: Jessica Kingsley.

WILLIAMS, D. (1998). Autism and sensing: The unlost instinct. London: Jessica Kingsley.

YIRMIYA, N., SIGMAN, M. D., KASARI, C., \& MUNDY, P. (1992). Empathy and cognition in high-functioning children with autism. Child Development, $63,150-160$. 